Artículo recibido el 11 de julio de 2020; Aceptado para publicación el 28 de julio de 2020

\title{
Movimentos de (re) existência nas práticas pedagógicas de professores indígenas.
}

\section{Movements of (re) existence in the pedagogical practices of indigenous teachers}

\author{
Maria Aparecida Mendes de Oliveira ${ }^{1}$ \\ Enoque Batista ${ }^{2}$
}

\begin{abstract}
Resumo
Este texto é resultado de um trabalho de pesquisa, mas também de vivência e diálogo presente na relação entre uma professora não indígena e um professor indígena, de matemática, construído ao longo do trabalho e reflexão sobre a educação escolar indígena. Este diálogo ultrapassa as marcas de tempos e espaços, pois se constituem na relação estabelecida ao longo dos anos na universidade, na escola e na aldeia. Tem como objetivo apresentar os sentidos produzidos pelos autores, sobre a forma como percebemos os agenciamentos produzidos nas escolas, pela comunidade e pelas instituições externas, nas práticas de professores indígenas. Diferentes situações apontam que, ao lidarem com as condições colocadas pela educação escolar para os indígenas, e no momento reforçada pelo ensino remoto em tempos de pandemia, os professores indígenas produzem movimentos de (re) existência, nas fissuras e frestas da ordem/moderno colonial.
\end{abstract}

Palavras-chave: educação escolar indígena; professores de matemática; movimentos decoloniais;

\begin{abstract}
This text is a result of a research study, but also of the experience and dialogue of the relationship between a non-indigenous teacher and an indigenous mathematics teacher built over the course of the study and reflection on indigenous school education. This dialogue goes beyond the marks of times and spaces, as it constitutes the relationship established over the years in the university, in the school and in the village. It aims to present the meanings produced by the authors on how we perceive the influence produced in schools by the community and by external institutions in the practices of indigenous teachers. Different situations point out that, when dealing with the conditions posed by school education for indigenous people, and at the moment reinforced by education in times of pandemic, indigenous teachers produce movements of (re) existence in the fissures and crevices of the colonial /modern order.
\end{abstract}

Keywords: indigenous school education; mathematics teachers; decolonial movements

\footnotetext{
${ }^{1}$ Educadora não indígena, atua como formadora de professores, na área de matemática, do curso de Licenciatura Intercultural Indígena-Teko Arandu, da Faculdade Intercultural Indígena da Universidade Federal da Grande Dourados, FAIND-UFGD, Dourados-MS

${ }^{2}$ Educador indígena da Reserva Taquaperi, professor de matemática da escola Escola Municipal Indígena Nhande Reko Arandu, município de Coronel Sapucaia-MS
} 


\section{INTRODUÇÃO}

O trabalho com os povos indígenas Guarani e Kaiowá nos desloca do lugar de acomodação, da lógica acadêmica universalista produzida sob os auspícios da colonialidade ${ }^{3}$, e nos leva a ocupar lugares de produção de conhecimento e de reconhecimento da (re)existência de outras lógicas de produção de vida, presentes no contexto das escolas indígenas.

Neste texto percorremos os sentidos produzidos sobre as práticas pedagógicas, presentes em uma escola indígena a partir de diálogo e da vivência entre uma professora não indígena e um professor indígena. A problemática desenvolvida girou em tono da forma como os professores indígenas relacionam diferentes sistemas de conhecimento, indígena e não indígena, durante sua prática pedagógica na escola indígena e a forma como os professores indígenas produzem movimentos de fuga dentre as diferentes situações que perpassam pela sua atuação docente.

Os diálogos realizados, por meio de entrevistas, conversas e trocas de experiências ultrapassam as marcas do tempo e do espaço, pois acontecem ao longo da (trans)formação destes professores ${ }^{4}$ que se inicia em cursos de formação para professores indígenas Guarani e Kaiowá no Mato Grosso do Sul - no Curso Normal Médio Ara Verá e na Licenciatura Intercultura Indígena Teko Arandu - e se estende para os diferentes momentos de formação continuada e de constante diálogo sobre o trabalho do professor na escola indígena. É marcado pela intersubjetividade dos autores. O diálogo entre os professores, como já mencionamos, ocorreram em diferentes momentos, mas boa parte dos sentidos que aqui apresentamos foram produzidos em visitas à escola indígena, em observações das aulas e nas entrevistas concedidas pelo professor indígena, aqui transformadas em uma única narrativa.

A analítica que apresentamos é composta de diversos elementos que passam pela compreensão do cenário presente nas áreas Guarani e Kaiowá, nas quais as escolas indígenas ocupam lugar de interface entre as relações sociais que os grupos indígenas

\footnotetext{
${ }^{3}$ Para Mignolo (2015), o conhecimento produzido sob os auspícios da colonialidade se dá a partir do domínio básico da matriz oculta do poder colonial presente na retórica da modernidade, que não nos permite, ocupando apenas os espaços da academia, reconhecer "o folclore, a medicina nativa, o direito consuetudinário e mitos que contam histórias imaginárias do passado como fontes válidas de conhecimento, em oposição às verdadeiras narrativas históricas". (2015, p. 149).

${ }^{4}$ Destacamos que ambos, professor indígena e professora não indígena, passaram por processos de formação e transformação, seja como aluno ou como professora, respectivamente ou inversamente dos cursos de formação inicial e continuada dos quais participamos.
} 
Mendes de Oliveira, M. \& Bastidas. E. (2020). Movimentos de (re)existencia nas praticas pedagógicas de professores indígenas. Revista Latinoamericana de Etnomatemática, 13(1), 150-173. DOI:

10.22267/relatem.20131.41

estabelecem com as instituições externas. Percorremos um caminho de significação que parte da identificação de situações presentes no contexto de trabalho de professores indígenas em suas práticas de ensino de matemática nas escolas das aldeias onde moram e da especificidade da formação em um curso de Licenciatura Intercultural Indígena.

Para este trabalho constituímos uma estratégia narrativa, de escrita compartilhada, que possibilita o desenvolvimento de um paralelo sobre a forma como percebemos as práticas de professores indígenas de matemática desenvolvidas nas escolas indígenas, que são atravessadas pela organização social da comunidade e com pelas instituições externas. Procuramos dialogar com diferentes elementos presentes nestas práticas identificadas a partir da experiência do professor indígena, um dos autores deste texto.

A Educação Escolar Indígena (EEI) tem se apresentado, ao longo das últimas décadas, como demanda para a formação de crianças e jovens indígenas que atenda aos anseios das famílias, das secretarias de educação de das instituições formadoras. Ao lidarem com essas diferentes situações os professores indígenas revelam, em suas práticas pedagógicas, um traçado de linhas de resistência nas relações de interculturais, promovidas por meio da escola, que provocam movimentos de decolonialidade frente ao lugar que a escola ocupa, historicamente, no cenário destes povos e na construção de uma Educação Escolar Indígena (Oliveira, 2020).

Acrescentamos a esta narrativa uma reflexão, ainda inicial, sobre a situação que os professores indígenas se deparam atualmente, causada pelo necessário distanciamento social, imposto pela circulação do vírus Sars-CoV-2 (síndrome respiratória aguda grave - coronavírus 2) que trouxe, dentre muitas consequências para os povos indígenas, mudanças na forma de circulação de pessoas nas comunidades e a oferta de educação escolar via ensino remoto.

\section{UMA BREVE DESCRIÇÃO DAS ESCOLAS NAS ÁREAS INDÍGENAS}

De acordo com o censo de 2010, Mato Grosso do Sul concentra a segunda maior população indígena do país, estimada em 73.295 indígenas distribuídas em oito etnias: Atikum, Guarani Kaiowá, Guarani Ñandeva, Guató, Kadiwéu, Kiniquinau, Ofaié e Terena. Os Guarani e Kaiowá e Guarani Nhandeva (ambos falantes da língua Guarani) constituem a segunda população indígena com maior número, que, somados, contam com cerca de 52.000 pessoas, de acordo com Censo Demográfico do IBGE de 2010. Os 
Guarani estão divididos em dois grupos, na região Sul do estado de Mato Grosso do Sul: são os Kaiowá (ou Pãi Tavyterã, no Paraguai) e os Nandéva, nesta região identificados apenas como Guarani. ${ }^{5}$

Nas áreas Guarani e Kaiowá de Mato Grosso do Sul estão em funcionamento cerca de 30 escolas $^{6}$, sendo 27 escolas municipais que atendem da educação infantil ao ensino fundamental e três escolas estaduais de Ensino Médio. Até os anos 2000 a maioria das escolas em áreas indígenas ofereciam apenas as séries iniciais do ensino fundamental. A partir deste período, aumentou consideravelmente o número de escolas indígenas localizadas nestas áreas. Este aumento é decorrente do movimento, por parte dos indígenas, de reivindicação de abertura de salas de aula para atender as séries finais do ensino fundamental, considerando a dificuldade que as crianças indígenas possuem para concluir esta fase de estudos. Principalmente pelas situações de preconceito e dificuldades com a língua portuguesa.

A Reserva indígena Taquaperi, onde reside o professor indígena que subscreve este texto e na qual desenvolvemos nossos diálogos, está localizada no município de Coronel Sapucaia, fronteira com o Paraguai. Possui uma população predominantemente Kaiowá e ocupam um território de $1.776,9594$ ha com cerca de 3.317 habitantes. Nas proximidades desta reserva há dois grupos de famílias Kaiowá que ocupam duas áreas de retomada Kurussu Ambá I e II ${ }^{7}$.

Esta aldeia possui duas escolas a Escola Municipal Indígena Nhande Reko Arandu criada 2002 e a Escola Municipal Indígena Mboe Roy Arandu criada em 2014. Estas escolas oferecem da Educação Infantil ao Ensino Fundamental completo. Nas áreas de ocupação funcionam duas extensões uma em Kurusu $\mathrm{Amba}^{8}$ I a extensão Ndo Nhande Reko Arandu e outra em Kurusu Amba II a extensão do Mboe Roy Arandu, com salas multisseriadas de $1^{\circ}$ ao $5^{\circ}$ anos. Ao todo são 819 alunos matriculados da Educação Infantil as séries finais do Ensino Fundamental de acordo com o Censo Escolar de matrículas por modalidade da rede estadual e municipal de Grosso do Sul no períodos de 2017 a 2018.

\footnotetext{
${ }^{5}$ No decorrer do texto será usada a denominação Kaiowá e Guarani como referência às duas etnias, considerando a forma como estes se auto identificam.

${ }^{6}$ Estes dados foram obtidos do Censo Escola 2017-2018 de MS, disponível na página da Secretaria Estadual de Educação https://www.sed.ms.gov.br/censo-escolar-6/. O número de escolas indígenas foi identificado nas planilhas que apontam as Matrículas por Etapa e Modalidade de Ensino da rede Estadual e Municipal.

${ }^{7}$ Kurussu Ambá I e II, são áreas de retomada, que estão localizadas próximas a reserva.

${ }^{8} \mathrm{O}$ processo de reocupação também tem sido de conflito e violência ao longo dos últimos anos.
} 
Mendes de Oliveira, M. \& Bastidas. E. (2020). Movimentos de (re)existencia nas praticas pedagógicas de professores indígenas. Revista Latinoamericana de Etnomatemática, 13(1), 150-173. DOI:

10.22267/relatem.20131.41

Nesta área os alunos cursam o Ensino Médio em uma extensão de uma escola urbana, na Missão Evangélica, que está localizada em uma área contigua a da reserva.

Esta breve descrição está neste texto para nos localizarmos geograficamente, no território em que as escolas indígenas estão e em que contexto o professor indígena atua. Entendemos a escola também como um "território de fronteira" no território hoje ocupado por estes povos, produto de processos violentos de deslocamento, de esbulho, e de luta contínua enfrentadas por estas comunidades (Oliveira e Orjuela-Bernal, 2020).

A situação fundiária em Mato Grosso do Sul e as transformações históricas, econômicas e sociais vivenciadas pelos Guarani e Kaiowá é bastante complexa e permeada pela expropriação de seus territórios, por disputas violentas entre índios e fazendeiros, além dos inúmeros tipos de violência vividos por esta população ao longo de sua história ${ }^{9}$. É num contexto de violência/apropriação, como coloca Santos (2010), ainda presente na relação colonialista imposta às comunidades indígenas, que vivem os povos Guarani e Kaiowá.

Ao se estabelecer como espaço de fronteira a escola indígena se constitui em um espaço que une dois mundos, onde ocorrem processos de tradução da instituição e da aprendizagem escolar a ambientes sócio culturais diversos (Tassinari, 2001). Ainda que, nas definições atuais legais ${ }^{10}$, os indígenas possuam a prerrogativa de elaborarem suas

\footnotetext{
${ }^{9}$ Não nos aprofundaremos nestas situações de conflito e violência contra os povos indígenas deste Estado. Remeto o leitor a acessar os "Relatórios de Violência contra os Povos Indígenas do Brasil" publicados, anualmente desde 2003, pelo CIMI - Conselho Indigenista Missionário, disponíveis em https://cimi.org.br/observatorio-da-violencia/edicoes-anteriores/. Estes relatórios se constituem num importante instrumento de denúncia das violências sofridas pelos povos indígenas, e é possível verificar que a situação de violência sofrida pelos Guarani e Kaiowá aumenta a cada ano, como destacado por Don Erwin Karutter, na edição 2006-2007, em que afirma que, dentre as regiões do país, "de maneira particular no Mato Grosso do Sul, envolvendo o povo Guarani Kaiowá, e sob determinados aspectos, tais violências aumentaram nos dois últimos anos. Continua sendo chocante o número e os tipos de violências sofridas pelos povos indígenas naquele estado, notadamente os inúmeros e persistentes suicídios, hoje sendo praticados na sua maioria por crianças e adolescentes Guarani Kaiowá" (2007, p.07).

${ }^{10}$ Decreto presidencial n 26 de 1991, que inclui as escolas indígenas no Sistema Nacional de Educação; a Lei de Diretrizes e Base da Educação - LDB 9.394/96, nos artigos 26, 32 e, mais especificamente, nos artigos 78 e 79; o Parecer 14/99, do Conselho Nacional de Educação, de 14 de setembro de 1999; a Resolução 03/99, do Conselho Nacional de Educação, de 10 de novembro de 1999, que, entre outras definições, cria a categoria de Escola Indígena; o Plano Nacional de Educação (Lei 10.172 - 9 de janeiro de 2001) que traz um capítulo sobre Educação Escolar Indígena; o Decreto Presidencial 6.861 de 27 de maio 2009, que aborda a organização territorial da educação escolar sob a definição de territórios etnoeducacionais; a Resolução $\mathbf{N}^{\mathbf{0}}$ 5, de 22 de junho de 2012, que estabelece as Diretrizes Curriculares Nacionais para a Educação Escolar Indígena na Educação Básica, os Referenciais Para a Formação de Professores Indígenas (2001); e a Resolução $\mathbf{N}^{\mathbf{0}} \mathbf{1}$, de 7 de janeiro de 2015, que Institui Diretrizes Curriculares Nacionais para a Formação de Professores Indígenas em cursos de Educação Superior e de Ensino Médio e dá outras providências.
} 
próprias propostas pedagógicas, estas estão associadas ao modelo escolar de referência, pautados pelas políticas nacionais e locais, pois estão inseridas no sistema nacional de educação.

Os regimes próprios de produção de conhecimento de diferentes povos passaram por processos de subalternização e continuam sendo, na medida em que lhes são impostos políticas homogêneas para a educação escolar, calcadas em um modelo colonialista, fundado no ideário da modernidade. Para Maldonado-Torres, a colonialidade

[...] refere-se a padrões de longa data de poder que surgiram como resultado do colonialismo, mas que definem a cultura, o trabalho, as relações de intersubjetividade e a produção de conhecimento muito além dos limites estritos das administrações coloniais. Assim, embora o colonialismo anteceda a colonialidade, a colonialidade sobrevive ao colonialismo. Ela é mantida viva nos livros, nos critérios de desempenho acadêmico, nos padrões culturais, no senso comum, na autoimagem dos povos, nas aspirações dos sujeitos, e em muitos outros aspectos da nossa experiência moderna. Em certo sentido respiramos a colonialidade e a modernidade diariamente. (2007, p. 131, tradução minha)

O mundo moderno colocou na mente e no ser de cada um de nós o conceito de conhecimento universal, que todos devemos conhecer. Isso não é diferente para os povos indígenas. O que tem sido produzido pelos povos indígenas, e mais especificamente pelos Guarani e Kaiowá, é um movimento de resistência a este processo. A educação bilíngue, concebida e proposta pelos povos indígenas como prática de enfrentamento às políticas educativas integracionistas, homogeneizantes, colonizadoras e as reformas desiguais de poder, tem um caráter claramente identitário e político reivindicativo (Walsh, 2009).

A discussão sobre a perspectiva da interculturalidade está inserida nesta complexidade, que vai para além de afirmar que essa se dá no encontro entre duas culturas, pois, quando tratamos dos povos indígenas em geral e dos Guarani e Kaiowá em particular, estes encontros se deram e se dão por meio de processos de colonialidade. A Interculturalidade, mais do que a simples relação entre culturas, pressupõe a visibilização de outros processos de construção de conhecimentos, de práticas políticas, sociais e de formas distintas de pensar e de atuar contra a modernidade/colonialidade (Walsh, 2012, p.53-54). A Interculturalidade é entendida como um movimento que representa

[...] processos dinâmicos e de dupla ou múltipla direção, repletos de criação e de tensão e sempre em construção; processos enraizados nas brechas culturais reais e atuais, brechas caracterizadas por assuntos de poder e pelas grandes desigualdades sociais, políticas e econômicas que não nos permitem relacionarmos equitativamente e processos que pretendem desenvolver sociedades e responsabilidades compartilhadas. (Walsh, 2009, p. 47, tradução minha) 
Mendes de Oliveira, M. \& Bastidas. E. (2020). Movimentos de (re)existencia nas praticas pedagógicas de professores indígenas. Revista Latinoamericana de Etnomatemática, 13(1), 150-173. DOI:

É fundamental perceber que as relações de saberes, estabelecidas no modelo imposto pelas estruturas, sistemas de poder e pelos conhecimentos coloniais, são mantidas e reproduzidas pela escola, e ainda guiam os modos de ser e de se perceber no mundo. Desta forma, interculturalidade e decolonialidade são projetos que estão ligados à luta por uma escola indígena diferenciada e sempre em construção, permeada por uma série de tensões.

A escola na área indígena é constantemente atravessada por movimentos de desterritorialização e reterritorialização. Para Maria do Remédio de Brito (2012) o conceito de território é de certa forma um agenciamento, sendo possível ser territorializado e desterritorializado. Assim, "As territorialidades são, pois, atravessadas, de um lado a outro, por linhas de fuga que dão prova da presença, nelas, de movimentos de desterritorialização e reterritorialização" (Deleuze; Guattari, F. 1995, p. 71, citado por Brito, 2012)". É a partir deste contexto que construímos esta narrativa produzida a partir de dois olhares, o de fora da cultura (o da professora não indígena) e o de dentro (do professor indígena), transformadas aqui em uma só voz.

\section{MOVIMENTOS DE (RE) EXISTÊNCIA: OS ATRAVESSAMENTOS DO ESTADO E DAS FAMÍLIAS}

É no território, ocupado pelas escolas indígenas, que os professores indígenas de matemática desenvolvem suas práticas pedagógicas. Estes professores, diante da ambiguidade que a escola traz, tecem "linhas de fuga" ou "fios de decolonialidade" ao modelo de racionalidade colonialidade. Produzem seus modos próprios - nhande reko mbo'e - de ensinar.

As escolas não estão alheias a estes movimentos, no trabalho dos professores indígenas em sala de aula, mesmo que fortemente influenciados por uma "educação maior"11 (Gallo, 2012) estes produzem linhas de fuga. O conceito de "educação maior" apresentado por Silvio Gallo, é consoante ao modelo de escola colonialista, que como uma máquina produz e reproduz processos a colonialidade do poder, do ser e do conhecimento. Para o autor, uma "educação menor" é um ato de revolta e resistência.

\footnotetext{
${ }^{11}$ Uma "educação maior" de acordo com Silvio Gallo é a proposta pelas políticas públicas de educação "dos parâmetros, das diretrizes, aquela da constituição e da LDB, pensada e produzida pelas cabeças bempensantes a serviço do poder. É aquela instituída e quer instituir-se, fazer-se presente, fazer-se acontecer." (2012, p. 173).
} 
[...] revolta contra os fluxos instituídos, resistência às políticas impostas; sala de aula como trincheira, como a toca do rato, o buraco do cão. Sala de aula como espaço a partir do qual traçamos nossas estratégias, estabelecemos nossa militância, produzindo um presente e um futuro aquém ou para além de qualquer política educacional. Uma educação menor é uma atitude de singularização e militância (Gallo, 2015, 173)

Nessas linhas que tecem, ao mesmo tempo que se prendem aos agenciamentos ${ }^{12}$ de dentro e de fora da escola indígena - dos movimentos indígenas, da própria comunidade, das secretarias municipais de educação e dos locais de formação - levam estes fios a se prenderem a uma rede, os quais dão forma a uma escola diferenciada, numa perspectiva intercultural e crítica. São estas linhas de fuga produzidas pelos professores indígenas em suas práticas pedagógicas na escola ou na comunidade, que produzem uma "educação menor" que é permeada por diferentes agenciamentos que destacamos neste momento da escrita.

Ao chegar em uma escola indígena, encontraremos um prédio com salas de aulas, muito semelhante às escolas que encontramos na cidade. Ao olhar a partir de quem não é falante da língua é possível perceber que ao falarem em guarani, professor e alunos, processo de tradução para a língua guarani produzem outra interpretação sobre o assunto tratado. Mesmo que seguindo o currículo imposto para as escolas indígenas, que se espelha no currículo oficial, o professor indígena constroem processos de subversão da lógica implementada pelo currículo oficial.

Um expelo destes processos está relatado no trabalho de pesquisa do professor indígena Claudemiro Lescano, que em sua dissertação de mestrado, ao tratar dos processos próprios de ensino e de aprendizagem entre os Guarani Kaiowá apresenta, em determinado momento, a forma como os professores indígenas encaram as avaliações de aprendizagem aplicadas às escolas indígenas, pelos sistemas educacionais. $\mathrm{O}$ autor menciona que estas avaliações não dão certo nas escolas indígenas por que os professores indígenas entendem que este tipo de avaliação não é da escola indígena, é externa. De acordo com ele

Os professores não proíbem os alunos de participar e não se preocupam com o resultado que se dará para fora, se vai ser bom ou ruim, simplesmente não tem valor algum para eles. Quando são cobrados pelo resultado, têm uma resposta na ponta da

\footnotetext{
${ }^{12}$ Aqui me refiro ao conceito de "agenciamento" apresentado por Deleuze e Gattari, em Mil Patos, que trazem a definição de agenciamento em estreita ligação com o conceito de território. Afirmam que "os agenciamentos comportam estados e misturas de corpos, mas também de enunciados, de regimes de signos, em relações em conexões complexas. Os modos de vida caminham em relação com os enunciados, mas são também atravessados por linhas" (apud Marques, 2015)
} 
Mendes de Oliveira, M. \& Bastidas. E. (2020). Movimentos de (re)existencia nas praticas pedagógicas de professores indígenas. Revista Latinoamericana de Etnomatemática, 13(1), 150-173. DOI:

10.22267/relatem.20131.41

língua: "É uma prova dos Karai, dos brancos, não tem nada a ver com a gente, vem tudo em Português". Considera-se isso como resistência. Os professores indígenas consideram como avaliação aquilo que repercute na comunidade, aquilo que se enxerga acontecendo, quando o aluno faz a mudança na comunidade. (Lescano, 2016, p.104).

Há resistência a um modelo imposto é traduzida nas diferentes formas de subversão produzidas na escola indígena, na sala de aula em que se encontram professores e alunos indígenas. São movimentos presentes nas práticas próprias de ensinar matemática, que estão nas maneiras como os professores desenvolvem suas estratégias para lidar com os diferentes agenciamentos de fora e de dentro da comunidade. Da cobrança de famílias das secretarias de educação para que a língua de instrução nas séries finais do da formação recebida em um curso Licenciatura Indígena Intercultural aos diferentes modos de ser kaiowá e guarani presentes na sala de aula.

As escolas nas áreas indígenas Guarani e Kaiowá, são marcadas pela constante presença das famílias e das lideranças da comunidade. Também os professores indígenas em diferentes situações se constituem como lideranças ou são cobrados a desempenhar diferentes papéis como liderança nas comunidades. Por outro lado, a escola indígena, pertence ao sistema de educação nacional, que nos casos das escolas em áreas Guarani e Kaiowá, são administradas diretamente pelas Secretarias Municipais de Educação. A proximidade das secretarias, gerenciadas por não indígenas, leva a uma tensão entre o exigido no ensino da escola, a partir do currículo oficial, e o que os professores tem desenvolvido nas suas práticas pedagógicas. Esta tensão está relacionada, em grande medida, pela exigência de que a língua de instrução seja a Língua Portuguesa, que é a segunda língua (para os indígenas).

A forma como as secretarias atuam se constitui como elemento que atravessa as práticas dos professores, as mudanças de gestão, leva a descontinuidades nas propostas e na busca por uma educação diferenciada intercultural e bilíngue. Sempre que a política no município muda, a política na escola indígena também muda.

Mesmo com este currículo que vem de fora, os professores indígenas procuram organizar suas aulas partindo dos conhecimentos indígenas. Dificilmente conseguem acompanhar o que determina o Projeto Político Pedagógico - PPP atual da escola, pois foi copiado de outra escola não indígena, os conteúdos são muito soltos, apresenta só uma lista de conteúdo. 
A mistura das duas línguas, é uma forma encontrada para atender as demandas apresentadas pelas famílias e as secretarias de educação. Se fala em sala de aula na língua portuguesa, na língua guarani e na linguagem matemática. Quando o professor fala em língua Guarani os alunos entendem melhor. Um exemplo que podemos apresentar de tal situação é sobre a explicação da formula de baskhara para a resolução das equações de segundo grau:

$$
\Delta=b^{2}-4 a c
$$

Como o desenho da letra delta se assemelha a de uma casinha o professor usa a palavra "oga $i$ " para traduzir, pois se falar delta o aluno não vai entender. Ao mesmo tempo em que se faz estas correspondências para a língua Guarani, também está presente, na ação do professor indígenas, uma preocupação com os alunos quando vão para outras fases do ensino, pois em muitos casos os professores são não indígenas. O que se percebe é que os alunos possuem um conhecimento básico de matemática dos anos anteriores das séries finais do Ensino Fundamental muito fraco. Na organização das aulas é necessário que o professor inicie trabalhando com as dificuldades que o aluno apresenta independente do que está no currículo daquele ano.

A forma como os professores indígenas "driblam a lógica" do currículo apresentado pela secretaria, se configura como um potencial movimento de oposição as lógicas empreendidas no interior das escolas nas aldeias. Ele assume posicionamentos e promovem movimentos de resistência, de transgressão. Produzem uma resistência que não consiste apenas em uma revolta contra o currículo imposto, as regras colocadas em jogo na escola indígena, mas em criar modos próprios de ação pedagógica.

A forma como está organizado o currículo da escola indígena, imposto pelas secretarias, ao serem conduzidos pelos professores indígenas se desenvolvem de maneira distinta ao “esperado". Engendram novos espaços e tempos que instituem outras relações pedagógicas (Gallo, 2015). O que entra em jogo são as práticas indígenas trazidas para o interior da escola, a partir da presença destes no espaço escolar (dos professores, dos alunos de da comunidade), uma "educação menor", e as práticas presentes no currículo prescrito, uma "educação maior". No desenvolvimento de suas práticas pedagógicas “educação maior" e a "educação menor" produzidas não se opõe,

Não podemos entende-las numa relação binária: uma ou outra. Aprendemos com Deleuze a aposta na disjunção inclusiva, uma lógica da diferença, que faz proliferar: e, e, e, ...Educação maior e educação menores. Há como que uma justaposição de 
Mendes de Oliveira, M. \& Bastidas. E. (2020). Movimentos de (re)existencia nas praticas pedagógicas de professores indígenas. Revista Latinoamericana de Etnomatemática, 13(1), 150-173. DOI:

10.22267/relatem.20131.41

espaços, em que uns não substituem os outros, mas coexistem, com mais ou menos conflito, dependendo da situação. (Gallo, 2015, p. 85-86)

Algumas considerações apresentadas pelo professor indígena apontam para uma busca de um modo próprio de driblar as situações de tensão apresentadas na relação com as famílias e com a secretarias de educação. Se negocia o tempo todo ora considerando o currículo do "Estado", ora produzindo um modo próprio de selecionar o que entendem ser importante para a vida das crianças na relação da aldeia com a cidade. E desta forma vão produzindo negociações, traduções, na fronteira epistemológica ${ }^{13} \mathrm{em}$ que vivem.

A presença das famílias na escola, ao apresentarem a necessidade de que seus filhos lidem melhor com o mundo não indígena, coloca para os professores a necessidade de em suas práticas, criarem "formas outras de fazer e de viver" (Gallo, 2015, p.86) no contexto das situações vivenciadas pelos Kaiowá, instituídas pelo modelo de sociedade não indígena. Nessas práticas ao acreditarem no mundo e na escola, experimentam e inventam linhas de fuga na educação maior instituída por meio da escola. Concordando com Pereira, Colman e Lopes (2019), circulação entre diferentes formas de conhecer, permite aos professores indígenas o desenvolvimento de uma atitude crítica e reflexiva em relação ao seu próprio sistema de conhecimento, procurando novos sentidos e explicações para as situações que se colocam nesta relação (Pereira, Colma e Lopes, 2019).

Nesse sentido, os professores apontam para a construção de práticas que buscam dialogar com o modelo instituído pelas secretarias e o modelo apresentado na formação inicial que espera que o professor indígena que seja intercultural (Oliveira, 2017).

O professor indígena vivencia em sua prática em sala de aula algumas contradições existentes na busca de relação entre sistemas de conhecimento distintos. Por exemplo na formação continuada que recebem se discute a perspectiva de trabalho em sala de aula e na escola a partir de um tema gerador ${ }^{14}$. Mas, ao mesmo tempo é necessário questionar até que ponto se pode um determinado tema que é problematizado por eles e que está relacionado com a situação de vida em que se encontram as comunidades indígenas. $\mathrm{O}$ que é mais evidente é que nas séries iniciais é mais fácil trabalhar com o tema gerador,

\footnotetext{
${ }^{13}$ Mignolo (2015), define fronteiras epistemológicas, nas fronteiras onde a diferença colonial se faz tanto visível quanto lacerante.

${ }^{14} \mathrm{Na}$ formação saberes indígenas assim como nos cursos como Ara Verá, se reforça a ideia do trabalho em sala de aula a partir do "tema gerador". Termo presente na obra de Paulo Freire, Pedagogia do Oprimido. Trata-se de um trabalho que busque elementos da cultura indígena para a reprodução dos conhecimentos escolares.
} 
pois se tem um professor para todas as áreas, o conhecimento não é tão fragmentado. Quando o aluno está no $6^{\circ}$ ao $9^{\circ}$ o ensino é dividido por áreas de conhecimento e é fragmentado e os conhecimentos da matemática Guarani e Kaiowá não batem com a lista de conteúdos que são prescritos pelo currículo da escola. Para os Guarani e Kaiowá o conhecimento não é fragmentado. Estudamos e fomos formados nas caixinhas, mas o conhecimento Guarani Kaiowá, tendo como base a cosmologia própria são um só.

A escola, da forma como se apresenta dificulta a possibilidade de diálogo entre os modos tradicionais de explicar e compreender, a cultura escolar produz outras formas de compreensão e organização do conhecimento. Destacamos por exemplo que a forma como o tempo está organizado na escola, aulas de 50 minutos, não possibilita a articulação entre o os conhecimentos tradicionais, ou o modo de ensinar tradicional, com o modo de conhecer não indígena. Em quatro aulas semanais fracionadas não é possível fazer este diálogo. São outras geografias de produção de conhecimento, de produção do ser, distintos lugares de enunciação.

O reconhecimento desta diferença e o colocar em cheque a noção de diálogo possível entre dois sistemas de conhecimento distintos, remete a reflexão sobre os sentidos produzidos para uma educação intercultural na escola indígena. Não se trata apenas de promover o diálogo, que de certa forma pode produzir armadilhas levando a sobreposição dos conhecimentos escolares aos conhecimentos indígenas. Mas, de reconhecer as diferenças entre estes conhecimentos, de questionar a ordem estabelecida por uma lógica dominante, com a produção de "modos outros" de ensinar que pode ser considerado como decolonial. O que percebemos são as fissuras presentes nas práticas pedagógicas dos professores indígenas, ao modelo colonialista da escola (Walsh, 2017).

$\mathrm{O}$ discurso de necessidade de buscar o diálogo entre os conhecimentos indígenas e conhecimentos escolares em sala de aula, é muito frequente e se naturaliza no discurso dos professores indígenas. No entanto, ao questionar esta possibilidade colocamos em evidencia as situações destacadas por Pereira, Colman e Lopes (2019), ao afirmarem que nestas relações entre conhecimentos distintos, ava reko e karai reko se comunicam e se conectam, além de se oporem. Oposição versus conexão/apropriação oscilam como figura e fundo, sem que a proeminência promova um eclipse total da outra.

\section{OS PROCESSOS DE TRADUÇÃO PRODUZIDOS EM SALA DE AULA;}


Mendes de Oliveira, M. \& Bastidas. E. (2020). Movimentos de (re)existencia nas praticas pedagógicas de professores indígenas. Revista Latinoamericana de Etnomatemática, 13(1), 150-173. DOI:

$10.22267 /$ relatem.20131.41

Já apontamos, neste trabalho, que a escola indígena, ou a escola nas comunidades indígenas Guarani e Kaiowá, se constituem como um espaço onde circulam diferentes formas de conhecimentos. Como espaços de fronteira (Tassinari, 2001, Mignolo, 2015). Neste espaço acontecem traduções entre diferentes formas de conhecimento e também os relacionados aos conhecimentos da matemática escolar para o universo Guarani e Kaiowá. Em sala de aula os professores indígenas acionam diferentes dispositivos para ensinar matemática, dialogando com o currículo oficial, produzindo diferentes processos de tradução, de negociação entre sistemas de conhecimento distintos. Ao explicar na língua Guarani para a criança o professor indígena traz elementos da cultura, do seu modo de pensar e estar no mundo. Pois de acordo com Hall (2006, p. 40), se produz significados ao se posicionarem no interior das regras da língua e dos sistemas de significado de nossa cultura.

A língua é um sistema social e não um sistema individual. Ela preexiste a nós. Não podemos, em qualquer sentido simples apenas expressar nossos pensamentos mais interiores e originais; significa também ativar a imensa gama de significados que já estão embutidos em nossa língua e em nossos sistemas culturais.

No sentido apontado por Hall (2006), na constituição do sujeito, a linguagem e o conhecimento estão interligados. Isso porque, segundo as considerações do autor, a língua constitui um sistema de referências sociais. Ainda a este respeito, Jackeline R. Mendes aponta que:

[...] a compreensão das crianças índias de como participar individualmente e demonstrar competência diferia consideravelmente do que era esperado na classe. Phlips (1972) acrescenta nesse trabalho que as variações culturais dos padrões sociolingüísticos, ou estruturas de participação, não são reconhecidos pelas escolas, resultando em dificuldades de aprendizagem e sentido de inferioridade nas crianças, apontando que são necessárias mudanças nas estruturas em sala de aula. (1995, p. 18)

A partir de exemplos de trabalho onde a autora faz uma comparação entre uma sala de aula com professor índio e outra com professor não-índio, Mendes (1995) mostra como as más interpretações ocorridas no plano linguístico podem determinar falsas avaliações que comprometem a motivação e a compreensão do aluno em sala de aula, tornando-se, de certa forma, um dos fatores que se relacionam ao insucesso e à evasão escolar de alunos de classes culturalmente minoritárias. As diferenças culturais de organização de fala determinam, portanto, um papel importante na aprendizagem e na linguagem estabelecida em sala de aula pelo professor. 
Há dificuldades em trazer um conhecimento, ou uma explicação de conceito matemático para a língua guarani. Como exemplo consideramos as operações de adição, subtração, multiplicação e divisão. A tradução de alguns conceitos não responde aos modos de conceber dos Guarani e Kaiowá. Muitas coisas têm limite de aprendizagem. Algumas matemáticas não aparecem na educação indígena. Muitas vezes se tenta traduzir para o guarani o que não é real para as pessoas na aldeia, o que traz uma complicação ainda maior para a aprendizagem. Por exemplo, a raiz quadrada, a fração, constituem objeto de estudo de uma matemática que não existe no sistema de conhecimento guarani. Mas, tem que ser ensinado na escola. O conhecimento entre os indígenas se aproxima do erjapo Kuaa (saber fazer), ou seja, "tem que ser na prática o aprendizado" e Ara kuaa (conhecer o tempo/espaço), (Kuaa, pode ser traduzido como saber, entender, compreender e ara é uma palavra que significa tempo e espaço ao mesmo tempo).

Diante do tensionamento das duas línguas na escola, a língua portuguesa e a língua guarani. Os professores indígenas deixam claro que a compreensão dos conceitos ou ideias matemáticas apresentadas em sala de aula, são possíveis na medida em que buscam um sentido para estes conceitos, na língua materna das crianças. Isso nos leva a uma questão sobre os processos de tradução que são produzidos na sala de aula e para a forma como estes tem criado linhas de fuga para o modelo que o "Estado" impõe a escola indígena.

A forma como estes professores lidam com o universo das duas línguas implica na tentativa de transposição de uma linguagem para o terreno de outra linguagem, dos conhecimentos e práticas de vida indígena, para a linguagem da matemática escolar. $\mathrm{Ou}$ inversamente, da maneira como os indígenas realizam esta tradução cultural, buscando a transposição de uma linguagem da universidade para o universo da cultura indígena, e posteriormente da escola indígena. De qualquer forma, como reforçado por Monteiro, ao destacar a complexidade presente no ato de traduzir, ela tem ocorrido nas salas de aulas, nas escolas indígenas. Para o autor

A tradução será sempre uma interpretação ou uma versão do texto original, que ganha novos sentidos com os novos usos que serão dados nos sistemas da cultura de chegada. Dessa forma, em acordo com as reflexões propostas por Ricoeur, a tradução poderá exercer um papel central diante das possibilidades de trocas interculturais, desde que seja possibilitado ao professor indígena uma formação segura em seu papel como professor indígena, participante de uma cultura diferenciada, que se expressa e se comunica por meio de sua língua (Monteiro, 2016, p. 92) 
Mendes de Oliveira, M. \& Bastidas. E. (2020). Movimentos de (re)existencia nas praticas pedagógicas de professores indígenas. Revista Latinoamericana de Etnomatemática, 13(1), 150-173. DOI:

10.22267/relatem.20131.41

Estes processos de tradução cultural se dão em condição de negociações fronteiriças. Homi Bahabha coloca a questão da tradução cultural como um elemento de resistência, nos processos de transformação e negociação, associadas ao ato de viver em condição de fronteira.

Os processos de tradução cultural estão imbuídos de relações de poder. Neste sentido, a busca por uma educação diferenciada, intercultural, pode ser entendida, não só como lugar de resistência, como é muito forte no discurso dos indígenas, mas também como lugar de produção de conhecimentos outros, nos processos de "tradução intercultural". Para Boa Ventura de Sousa Santos, a tradução intercultural assume um lugar fundamental nas epistemologias do sul, "por ser um instrumento decisivo nas aprendizagens recíprocas entre grupos sociais oprimidos que, em diversas regiões e tempos históricos, resistem e lutam conta as diferentes formas de dominação de que são vítimas” (2019. p. 295).

É importante considerarmos o lugar da escola na vida das crianças indígenas, pois o problema com a linguagem não está relacionado só ao fato de circularem duas línguas e dois sistemas de conhecimentos neste ambiente. Quando se explica o conteúdo para os alunos, mesmo que na língua guarani e se pergunta a ele na língua, mesmo assim, os alunos não falam, não respondem às perguntas. Portanto a língua não é o único problema. O problema parece que é a escola, a sala de aula, o que ela representa na vida dos alunos, pois fora da escola eles falam. Isso também é possível perceber no relato de Eliel Benites que, com a idade escolar, começou a frequentar a escola da aldeia, a conviver com pessoas diferentes da própria aldeia e a conhecer também a professora não indígena. "Para mim era um mundo diferente, mesmo dentro da aldeia; os espaços públicos da aldeia eram como espaços de ninguém e diferentes". (Benites, 2014, p.61)

O esforço que os professores indígenas fazem em sala de aula para buscarem correspondência de uma língua para outra, de um sistema de conhecimentos para outro é hercúleo. Pois, este processo de tradução não é simples como muito bem analisa Monteiro (2016), que em seu trabalho junto aos povos indígenas Xerente e Karajá destaca que ao vivenciar as práticas de professores indígenas em sala de aula foi possível perceber que este processo envolve além da linguagem, a cosmovisão do grupo nas relações que estabelecem com o mundo, a partir do local que esse grupo ocupa neste mesmo mundo. Os professores Guarani e Kaiowá ao trabalharem os conteúdos em sala de aula, estão, o tempo todo, fazendo traduções de um sistema de conhecimentos para outro. Ao buscarem 
em suas referências da língua étnica e, consequentemente, nos sistemas de significados de sua cultura, em muitos momentos não encontram elementos para explicar determinados conceitos. Ao buscarem significar um sistema de conhecimentos a partir de outro sistema, estes estão produzindo outros conhecimentos.

\section{OS DIFERENTES MODOS DE SER KAIOWÁ E GUARANI PRESENTES E A ESCOLA.}

Considerar os povos indígenas como uma unidade, bem como a educação escolar indígena em geral, é um dos principais equívocos ao se pensar as políticas de educação para estes povos, pois o sujeito Kaiowá não é único, e são produzidos de forma plural. No interior de uma mesma aldeia existem diferentes modos de ser professor em sala de aula, pois existem diferentes modos de ser Guarani e Kaiowá. As transformações pelas quais passam na relação com a sociedade envolvente interferem na postura do professor e dos alunos $\mathrm{O}$ professor indígena tem que lidar com diferentes configurações familiares na aldeia, pois cada família ensina de um jeito seus filhos, com um modo próprio e costumes diferentes. E os alunos trazem para a sala de aula estes diferentes modos de ser. Ava kaiowa reko kuera, modos múltiplos de ser kaiowa, e estas diferenças estão também presentes na sala de aula.

O antropólogo indígena Tonico Benites destaca que cada grupo familiar produz um modo de ser peculiar (teko laja kuera), conformando uma realidade contemporânea como sendo caracterizada pelo teko reta: o modo de ser múltiplo do conjunto destas famílias indígenas. De acordo com o autor, o teko reta continua sendo, no entanto, um ñande reko, um "nosso modo de ser" sempre contraposto ao karai kuera reko, modo de ser do nãoíndio" (Benites T., 2009, p.20).

Para os indígenas, antigamente, existia apenas uma categoria de criança Te'ýi tee, um modo próprio de educar a criança, não havia uma classificação de criança. Hoje, nas escolas indígenas, os professores precisam lidar com a classificação das crianças, em faixas etárias e em seriação escolar.

Nesse sentido, Cariaga (2012) ao propor uma discussão sobre como a criança se insere gradativamente nos espaços político-familiares entre os Kaiowá, nos ajuda a compreender que elas trazem para a escola estas diferentes configurações. De acordo Pereira (2004) as unidades sociológicas kaiowá combinam elementos de distintos campos da vida social, abrangendo o parentesco, alianças políticas e intercâmbio religioso. Estas unidades são 
Mendes de Oliveira, M. \& Bastidas. E. (2020). Movimentos de (re)existencia nas praticas pedagógicas de professores indígenas. Revista Latinoamericana de Etnomatemática, 13(1), 150-173. DOI:

10.22267/relatem.20131.41

enraizadas em categorias do pensamento próprias aos Kaiowá, compondo um conjunto que apresenta considerável coerência lógica quando considerado em seus próprios termos. (Pereira, 2004, p. 156, apud Cariaga, 2012)

Sobre esta questão, Pereira (2004) aponta que "velho e/ou antigo" ou "novo e/ou jovem" não expressam apenas categorias de idade, mas falam de percepções organizacionais das famílias Kaiowá, demonstram aspectos referentes à tradição e à transformação, em camadas conflitantes de tempo e espaço. Isso resulta na reinvenção de múltiplas camadas de tempos e espaços kaiowá, mesmo num cotidiano marcado pela predominância da dinâmica imposta pela sociedade nacional. Para o autor a alternativa para o impasse seria reatualizar o primeiro tempo, o que implica em "valorizar o que é nosso" (Pereira, 2004, p. 273)

Para as famílias Kaiowá, principalmente nas reservas, foram apresentadas diversas estratégias educativas e um modelo de vida ideal, etnocêntrico, com o intuito de desvalorizar os métodos próprios de educação e de ser e viver das famílias indígenas. Assim, começou-se a ensinar e socializar o modo de se vestir, alimentar, namorar, casar, punir, adorar a Deus, tratar as doenças, ler e escrever etc. Em decorrência disso, as famílias passaram a se deparar com um leque de possibilidades de experimentar elementos culturais diversificados. De acordo com Benites, T. (2009) um líder político Kaiowá (mburuvicha) argumentou o seguinte, numa reunião intercomunitária (Aty Guasu) no ano de 2008, em relação aos elementos culturais apresentadas pelos agentes coloniais não-indígenas:

Há muito tempo atrás, os karai vieram nos mostrar os seus objetos, além do seu modo de vida. Ensinaram-nos diversos tipos de culturas, por isso, hoje existem vários modos de ser e viver assumidos por nós. Por exemplo, os diversos contatos produziram variedades de estilos comportamentais como: as pessoas estudantes, crentes, bêbadas, violentas, progressivamente transformam-nos em Kaiowá esperto, sabido, crítico, mas mesmo assim, continuamos a ser exclusivamente Ava Kaiowá. (Benites T., 2009 p. 49-50)

Neste sentido, de acordo para o autor o próprio kaiowá reconhece que não existe um modo de ser e viver homogêneo, visto que houve contato com diversos grupos sociais e apropriação de elementos culturais não-indígenas presentes na região. A socialização da criança Kaiowá e Guarani assumiu as formas de sociabilidade internas às comunidades e transformações históricas recentes no ambiente de vida. A escola, o posto de saúde e as 
agências do Estado quebram algumas regras presentes no modo de socialização das crianças no interior das áreas indígenas.

A escola as vezes altera ou apresenta outras ticas de matema, que não são as mesmas presentes na cultura indígena. Por exemplo, a divisão em partes iguais, rompe uma lógica cultural. Para o professor indígena este modo de divisão expressa egoísmo. Em uma aula do $6^{\circ}$ ano explicando o conceito de divisão em partes iguais, as crianças questionaram. Uma delas perguntou: se o pai der dez reais para um filho tem que dar para outro. Um outro aluno disse que o pai dá mais para os mais velhos. As crianças não comem a maior parte e sim os adultos, primeiro serve pais depois as crianças, porque o adulto precisa de uma quantidade maior comida que a criança.

Este exemplo nos remete à questão de como são produzidos os processos de interculturalidade, nos quais se identifica que a busca de um diálogo entre diferentes formas de conhecer passa pelo reconhecimento e a percepção da diferença entre os diferentes sistemas de conhecimento. A interculturalidade também ocorre na afirmação, como se apresenta nas colocações de alguns destes professores sobre oposição entre os modos de conhecer a das (im) possibilidades de tradução (Monteiro, 2016), presentes neste diálogo que está colocado na escola indígena.

\section{E POR FIM QUE FORMAS DE (RE)EXISTENCIA SERÃO PRODUZIDAS EM TEMPOS DE PANDEMIA?}

Somada a estas situações e desafios que se colocam para o professor indígena em sua prática pedagógica, que narramos até aqui, os desafios são ainda maiores em tempos de distanciamento social, provocados pela COVID-19, que avança para os territórios indígenas. De acordo com relatório produzido pelo Núcleo de Métodos Analíticos para Vigilância Epidemiológica do PROCC/Fiocruz e EMAp/FGV, os povos indígenas, no Brasil, apresentam condições de desvantagem em comparação à população não indígena em inúmeros indicadores sociodemográficos e sanitários, com destaque para as populações residentes nas Terras Indígenas (TI), nas quais se observa, por exemplo, menor proporção de escolaridade formal, menor cobertura de saneamento e elevada mortalidade precoce. Um outro Relatório técnico divulgado por pesquisadores da Universidade Federal da Bahia (UFBA), Universidade Federal do Oeste da Bahia (UFOB) e Universidade Federal de Uberlândia (UFU) aponta que, em Dourados-MS, segunda maior cidade do Mato Grosso do Sul, a pandemia ainda está em fase de 
Mendes de Oliveira, M. \& Bastidas. E. (2020). Movimentos de (re)existencia nas praticas pedagógicas de professores indígenas. Revista Latinoamericana de Etnomatemática, 13(1), 150-173. DOI:

10.22267/relatem.20131.41

crescimento e não dá sinais de redução do número de casos confirmados da Covid-19. Até o momento da escrita deste texto, a Covid-19 avança para as cidades da região de Dourados em que estão localizadas as comunidades Guarani e Kaiowá.

Nesse senário são produzidos outros atravessamentos aos modos de ser destes povos, causadas por novas regras de comportamento para o combate à doença e as novas formas de organização social que ela traz. E isso se desdobra nas práticas desenvolvidas na educação escola. A rapidez com que tudo aconteceu, o sufoco e o medo além do atropelo das aulas remotas nos afetaram profundamente nestes tempos de pandemia. As escolas indígenas também tiveram que dar continuidade ao ano letivo, só que agora em uma outra modalidade que é o "ensino remoto", distante.

Num primeiro momento, as comunidades precisavam se organizar para entender a atual situação colocada pela pandemia. Entender e explicar o que significa o necessário distanciamento entre as pessoas e consequentemente da escola dos alunos. Entender a necessidade de isolamento, a não possibilidade de aglomeração, entre outras situações. Todos, professores, gestores e a comunidade, precisavam entender o que estava acontecendo. Os professores, por sua vez, passaram a assumir também o papel de explicar as famílias na comunidade a necessidade de novas formas de se relacionar diante do necessário isolamento social. A maior dificuldade é entender sobre este algo desconhecido, que muda a rotina da aldeia e da circulação de pessoas na comunidade.

Este entendimento passa, também, por um processo de tradução de palavras e significados estranhos aos indígenas como pandemia, isolamento, distanciamento, aglomeração, não compartilhamento, dentre outras palavras e significações que surgem neste novo senário. São processos de tradução que precisavam ser feitos para que as famílias entendam estes novos significados ${ }^{15}$. Para os indígenas tem sido difícil entender como levar este tempo de mudança, que foi tão rápido. Entre as famílias, na aldeia, o indígena é muito diferente de quem mora na cidade, pois se tem liberdade, não se tem limite de ficar em casa, não se tem muros como na cidade que gera limitação de movimentação e circulação.

\footnotetext{
${ }^{15}$ Para exemplificar esta dificuldade nos remetemos aos primeiros casos confirmados de COVID-19 na Reserva Indígena no município de Dourados, a maior dificuldade foi pensar as formas de isolamento para uma organização de famílias, que ser constituem em núcleos de até três ou quatro famílias muito próximas umas às outras. As pessoas tiveram que ser retiradas da aldeia, do seu núcleo familiar, e levadas para locais de isolamento na cidade. Muitos ne negavam a ir para eles locais e os professores e agentes de saúde na comunidade assumiram um importante papel neste processo de tradução desta nova situação no interior dos núcleos familiares.
} 
No campo da educação escolar veio mais uma coisa para aprender "o ensino remoto". Mudou todas as formas que se conhecia de relação com as famílias, com as crianças, de trabalho na escola, das ações pedagógicas. Os professores indígenas nunca passaram por este "tempo de fazer uma aula a distância". As Secretarias Municipais de Educação colocam, sem debate com a comunidade, o ensino remoto. As famílias e os professores estão tendo que fazer sem entender, é um fazer rápido, pois é uma determinação da secretaria de educação e a escola indígena pertence a ela.

No primeiro momento foi necessário pensar em estratégias de como distribuir estas atividades, e quais métodos de chegar aos alunos, considerando que o acesso à internet é algo tão remoto nas comunidades indígenas como é o conceito de "ensino remo". A educação escolar tem funcionado a partir de "aulas programas"16. O desafio que se apresenta para o professor indígena em tempos de pandemia, mais do que já tem sido, é inserir a educação escolar no fogo doméstico, pois esta não se encaixa no jeito Guarani e Kaiowá. Como levar a educação escolar para o fogo doméstico?

O "fogo familiar" ou "fogo doméstico" é tomado por Pereira (1999, p.81) como uma "unidade sociológica no interior do grupo familiar extenso", que expressa o lugar de formação da pessoa. A partir deste modelo de interpretação do sistema social, Cariaga (2012) destaca que “é no fogo que são acentuadas as relações de conviviabilidade e comensabilidade, denotando um sentido de expressiva coesão social" e se constitui num ambiente em que as crianças podem experimentar liberdade irrestrita para conhecer o mundo que as circunda.

Os professores indígenas encontram muita dificuldade em encontrar um jeito próprio, pois as aulas programadas se constituem de atividades que são elaboradas por cada professor, impressa e entregue para as famílias. E essas atividades tem que estar atrelada aos conteúdos escolares impostos via Secretarias de Educação e de acordo com os modelos de planejamento que encaminham para as escolas indígenas. $\mathrm{O}$ acesso à internet é um dos problemas que enfrentamos nas áreas indígenas, desta forma estas atividades orientadas precisam ser impressas e entregues as famílias, que recebem os trabalhos em forma de apostilas para fazerem sozinhos em casa.

\footnotetext{
${ }^{16}$ Materiais impressos, com atividades escolares que são levadas pelas famílias para as crianças desenvolverem em casa.
} 
Mendes de Oliveira, M. \& Bastidas. E. (2020). Movimentos de (re)existencia nas praticas pedagógicas de professores indígenas. Revista Latinoamericana de Etnomatemática, 13(1), 150-173. DOI:

10.22267/relatem.20131.41

As atividades vão prontas para as famílias, se inserem no "fogo doméstico" como um papel sem vida, como um ensinamento imposto. No fogo doméstico a educação indígena está em movimento na família na casa, se aprende na família. À distância ficou os ensinamentos da escola, de teoria e de outros conhecimentos escolares. A educação indígena é favorecida neste momento de pandemia, pois as crianças ficam mais próximas do fogo doméstico. Enquanto que a educação escolar permanece a distância e distanciada da realidade das comunidades.

A covid-19 não traz apenas uma doença, mas a necessidade de estabelecimento de novos modos de (re) existência, para os povos indígenas, também provocadas pela necessidade lidar com este tempo que ela impõe. E neste processo os professores indígenas em suas comunidades estão vivenciando novos modos de se organizar.

A diferentes situações que atravessam as práticas pedagógicas dos professores, conforme narramos durante este texto, somada ao cenário que se apresenta diante da pandemia, apontam para um entendimento de que os professores indígenas produzem movimentos de (re) existência.

Entendemos que é neste processo que se dá um movimento em que os professores indígenas vão produzindo suas práticas pedagógicas em direção à produção de conhecimentos de fronteira, e agora com mais um desafio que é levar a educação escolar para o fogo doméstico. Não sabemos ainda como isso se desdobrará, estamos vivendo o agora, com o peso da rapidez com que tudo está acontecendo, em um tempo que não é o tempo dos Guarani e Kaiowá.

\section{CONSIDERAÇÕES FINAIS}

Os professores indígenas em suas práticas pedagógicas, na escola indígena, são constantemente atravessados por distintas situações como apresentamos ao longo do texto. O modelo colonialista ainda desenvolve raízes nos sistemas educacionais brasileiros, e consequentemente nas escolas indígenas, e deixam marcas profundas na constituição do ser e nas concepções de saber que também produzem uma situação de desigualdade, aprofundadas em tempos de pandemia, no que se refere ao acesso a educação escolar para os indígenas. Estes sobrevivem e produzem alternativas e estratégias de resistências ao mesmo tempo em que lidam com situações limites que lhes são apresentadas. 
Procuramos trazer à tona aspectos produzidos no processo de interculturalidade vivenciado pelas comunidades, professores e alunos nas escolas indígenas e dos movimentos de resistência/existência que estes produzem em suas práticas pedagógicas. Acrescentamos as situações e desafios já vivenciados pelos professores indígenas novas condições, de isolamento social de preservação da vida em tempos de pandemia, traz para os professores, alunos e famílias indígenas novos desafios para a educação a serem desenvolvidas de forma distanciada.

\section{REFERÊNCIAS}

Benites, E. (2014). Oguata pyahu (uma nova caminhada) no processo de desconstrução e construção da educação escolar indígena da reserva indígena Te ýikue. 2014. 165 f. Dissertação (mestrado em educação) - UCDB, Campo Grande.

Benites, T. (2009). A escola na ótica dos ava kaiowá: impactos e interpretações indígenas. 2009. 105f. Dissertação (Mestrado em Antropologia Social). /MN/PPGAS/UFRJ, Rio de Janeiro.

Brito, M. (2017). Dialogando com Gilles Deleuze e Félix Guattari sobre a ideia de subjetividade desterritorializada. Alegrar, no09 - jun/2012. Acesso em: 15 mar.

Cariaga, D. (2012). As transformações no modo de ser criança entre os Kaiowá em Te’ýikue (1950 -2010). Dissertação (Mestrado em História) - UFGD, Dourados, 2012.

Gallo, S. (2015). Educação Menor: produção de heterotopias no espaço escolar. In Grupo Transversal (Org.). Educação Menor: conceitos e experimentações. (pp. 7588.) Curitiba: Appris.

Hall, S. (2006). A identidade cultural na pós modernidade. 11 ed. Rio de Janeiro: DP\&A,

Lescano, C. (2016). Tavyterã Reko Rokyta: os pilares da educação Guarani Kaiowá nos processos próprios de ensino e aprendizagem. 2016. 108f. Dissertação (mestrado em educação) - Universidade Católica Dom Bosco, Campo Grande.

Maldonado-Torres, N. (2007). Sobre la colonialidad del ser: contribuciones al desarrollo de un concepto. In. Castro-Gómes, S y Grosfoguel, R. (Org.). El giro decolonial: reflexiones para una diversidad epistémica más allá del capitalismo global. Bogotá: Siglo del Hombre Editores; Universidad Central, Instituto de Estudios Sociales Contemporáneos y Pontificia Universidad Javeriana, Instituto Pensar.

Mendes, J. R. (1995). Descompassos na interação professor-aluno na aula de matemática em contexto indígena.1995. Dissertação (Mestrado em Linguística Aplicada). IEL-UNICAMP, Campinas.

Mignolo. W. (2015). Habitar La Frontera Sentir y pensar la descolonialidad (Antología, 1999-2014). Barcelona. Edición: CIDOB y UACJ. 
Mendes de Oliveira, M. \& Bastidas. E. (2020). Movimentos de (re)existencia nas praticas pedagógicas de professores indígenas. Revista Latinoamericana de Etnomatemática, 13(1), 150-173. DOI:

$10.22267 /$ relatem.20131.41

Monteiro, A. \& Mendes, J. (2015). Etnomatemática como movimento de contraconduta na mobilização de sabres em práticas culturais. VI SIPEM- Seminário Internacional de Pesquisas em Educação Matemática. Anais. Disponível em: $<$ http://www.sbembrasil.org.br/visipem/anais/story_html5.html $>$. Acesso em: $20 \mathrm{de}$ fev. 2016.

Monteiro, A. \& Mendes, J. (2019). Saberes em práticas culturais: condutas e contracondutas no campo da matemática e da educação matemática. Periódico Horizontes, - USF - Itatiba, SP. (37). Disponível em $<$ https://revistahorizontes.usf.edu.br/horizontes/article/view/763>. Acesso em: $15 \mathrm{dez}$. 2019.

Monteiro, H. (2016). O ensino de matemática na educação escolar indígena: (Im) possibilidades de tradução. 2016. 173f. Tese (Doutorado em Ensino de Ciências e Matemática), UNICAMP.

Oliveira, M., \& Orjuela, J. (2020). Educação para indígenas e escolas indígenas dos Guarani e Kaiowá: um olhar crítico. REMATEC: Revista de Matemática, Ensino e Cultura, Ano 15, 33, p.p 95-111.

Oliveira, M. (2020) Nhande Reko Mbo'e: busca de diálogos entre diferentes sistemas de conhecimentos no contexto das práticas de professores de matemática Guarani e Kaiowá. Tese (Doutorado em Educação) - Faculdade de Educação, Universidade de São Paulo, São Paulo, 2020

Oliveira, M. (2017). Formação de professores indígenas de matemática: conhecimentos necessários em cenário intercultural. XI Seminário Sul-Mato-Grossense de Pesquisa em Educação Matemática, de 23 a 26 de maio de 2017. Anais. 1 (11), Campo Grande, MS. Disponível em: < https://periodicos.ufms.br/index.php/sesemat/article/view/3682>. Acesso em: 06 de jun. 2018.

Pereira, L., Colmam, R., \& Lopes. (2019). Knowledge dialogues: the role of Kaiowa and Guarani knowledge systems within the Intercultural Teacher Education programme of the Federal University of Grande Dourados, Brazil. Dutkansearvi 3 (2),. Disponível em: <http://dutkansearvi.fi/levi-marques-pereira-rosa-sebastianacolman-and-camila-emboava-lopes-knowledge-dialogues-the-role-of-kaiowa-andguarani-knowledge-systems-within-the-intercultural-teacher-education-program/>. Acesso em: 13 mai. 2020.

Pereira, L. (2004). Imagens Kaiowá do Sistema Social e seu Entorno. Tese (Doutorado em Antropologia Social) USP, São Paulo, SP.

Pereira, L. M. (1999) Parentesco e organização social Kaiowá. 1999. 251f. Dissertação (Mestrado em Antropologia Social) - UNICAMP, Campinas.

Santos, B. (2010). Para além do pensamento abissal: das linhas globais a uma ecologia de saberes In: Santos, B. \& Meneses, M. (Org.). Epistemologias do Sul. (pp. 3183). São Paulo: Cortez.

Santos, B. (2019). O fim do império cognitivo: a afirmação das epistemologias do Sul. Belo Horizonte. Editora: Autentica. 
Sed/MS (2018). Matrícula por etapa e modalidade de ensino - Rede Estadual e Municipal. Disponível em: https://www.sed.ms.gov.br/censo-escolar-6/. Acesso em 01 fev de 2018.

Tassinari, A. (2001). Escola Indígena: novos horizontes teóricos, novas fronteiras de educação. In: Lopes da Silva, A \& Ferreira A. M. (Org.). Antropologia, História $e$ Educação: a questão indígena e a escola. São Paulo/SP: MARI/FAPESP/Global Editora.

Walsh, C. (2017). Pedagogías Decoloniales. Práticas Insurgentes de resistir, (re)existir e (re)vivir. Serie Pensamiento Decolonial. Editora Abya-Yala. Equador.

Walsh, C. (2012). Interculturalidad, estado, sociedad luchas (de)coloniales de nuestra época. Quito: Universidad Andina Simón Bolívar / Ediciones Abya-Yala.

Walsh, C. (2009) Interculturalidad crítica y (de)colonialidad: Ensayos desde Abya Yala. Quito-Ecuador. Edicio nes Abya-Yala. 